\title{
Safety and efficacy of a new percutaneously implantable interspinous process device
}

\author{
Sven Rainer Kantelhardt • Elisabeth Török • \\ Jens Gempt • Michael Stoffel • Florian Ringel • \\ Carsten Stüer • Bernhard Meyer
}

Received: 8 June 2010 / Accepted: 5 July 2010 /Published online: 16 July 2010

(C) Springer-Verlag 2010

\begin{abstract}
Background Lumbar spinal stenosis is a degenerative disease of the elderly population. Although microsurgical decompression has shown good long-term results, percutaneous techniques could provide an alternative in the presence of significant comorbidities.

Method Eighty-seven interspinous process decompression devices (In-space; Synthes, Umkirch, Germany) were implanted percutaneously in up to three segments of 50 patients. Outcome was assessed directly after surgery, at

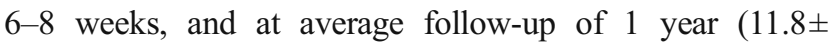
6 months). Assessment included complications, pain and spinal claudication, neurodeficit, time to recurrence of symptoms, and time to second surgery. Subgroups with additional low back pain at presentation and mild spondylolisthesis were analyzed separately.

Findings Intraoperative complications were rare (one misplacement and two cases of failed implantation); average operation time was $16.4 \pm 12.2$ min per segment. Initial response was very good with $72 \%$ good or excellent relief of symptoms. After a 1-year follow-up, $42 \%$ reported of lasting relief from spinal claudication. Thirteen percent of these complained about lasting or new-onset low back pain. A second surgery had been performed in $22 \%$. Subgroup analysis was performed for patients presenting
\end{abstract}

S. R. Kantelhardt · E. Török · J. Gempt · M. Stoffel · F. Ringel • C. Stüer $\cdot$ B. Meyer $(\square)$

Department of Neurosurgery, Technical University Munich, Ismaninger Straße 22,

81675 Munich, Germany

e-mail: Bernhard.Meyer@1rz.tu-muenchen.de

S. R. Kantelhardt

Department of Neurosurgery, University-Hospital Göttingen,

Göttingen, Germany with additional low back pain and spondylolisthesis patients. No significant differences could be noted between subgroups.

Conclusions The In-space is a percutaneous treatment option of claudication in patients with lumbar spinal stenosis. Compared with microsurgical decompression surgery, recurrence rate within 1 year is, however, high and the device seems not suitable for the treatment of low back pain. Therefore, the authors suggest that the device should presently be used primarily in controlled clinical trials in order to get more information concerning the optimal indication.

Keywords Interspinous process decompression (IPD) In-space $\cdot$ Lumbar spinal stenosis $\cdot$ Percutaneous

\section{Introduction}

Lumbar spinal stenosis is a result of degeneration of the lumbar spine and strongly correlated with older age [20, 28]. The most common symptom is spinal claudication with or without low back pain and alleviation in flexion of the spine [9]. Microsurgical decompression has been shown to adequately relieve the symptoms, and long-term results are very good $[1,2,7,10,18,19,29]$. Unfortunately, higher patient age is also associated with relevant comorbidity and thus aggravating the risk of anaesthesia and prolonged surgical procedures [3, 21, 22, 25]. Interspinous process decompression (IPD) techniques may offer a less invasive alternative for microsurgical decompressive surgery in lumbar spinal stenosis. Several implants have been introduced in the market. The In-space (Synthes, Umkirch, Germany) is a new implant strictly designed for percutaneous implantation with short operating times. We present the 
first single institutional experience concerning efficacy and safety of the device.

\section{Materials and methods}

\section{Patients}

Between November 2007 and August 2009, 50 patients were treated by percutaneous implantation of the In-space device (Synthes) in our institution (Fig. 1). Average patient age was $71.8 \pm 10.6$ years, gender ratio (male/female) was 34:16. The indication for implantation of the In-space was based on the presence of mild to moderate lumbar spinal stenosis as demonstrated on a preoperative magnetic resonance or computed tomography scan in one to three levels. Symptoms included spinal claudication in 44 patients, 16 of these had additional low back pain. One patient presented with isolated intermittent neurodeficit, one with isolated L5 radicular pain, and four with low back pain and fixed radicular pain only. In 12 of the patients, a mild spondylolisthesis (Meyerding ${ }^{\circ} 1$ ) without the presence of spondylolysis was diagnosed in one or two segments. Preoperative treatment included oral analgetics and physiotherapy in all cases. One patient underwent conventional decompression surgery 2 years previously to In-space implantation in the same segment (L3/4). Three patients had previously been operated by conventional decompression of other segments of the lumbar spine, two had undergone anterior discectomy of the cervicle spine, and one patient had undergone kyphoplasty (L4) prior to Inspace implantation at $\mathrm{L} 2 / 3$.

\section{Surgery}

Up to three In-space devices were implanted percutaneously in the affected segments. Intraoperative complications as well as time for surgery and required blood cell transfusions were recorded. After surgery, X-ray films were obtained in two planes to rule out/confirm misplacement of the implants for all patients.

\section{Follow-up}

During the postoperative hospitalization, postoperative neuroexaminations were performed and pain and mobility were assessed in the following categories: worse, same, slightly better, good, or excellent. Postoperative imaging studies, other than conventional X-ray (magnetic resonance imaging or computed tomography scans) were performed in
Fig. 1 Percutaneous implantation of the In-space device. a-c Insertion of a guiding wire and dilatation of the approach. Finally, the implant is inserted (d), and its wings were deployed (e)
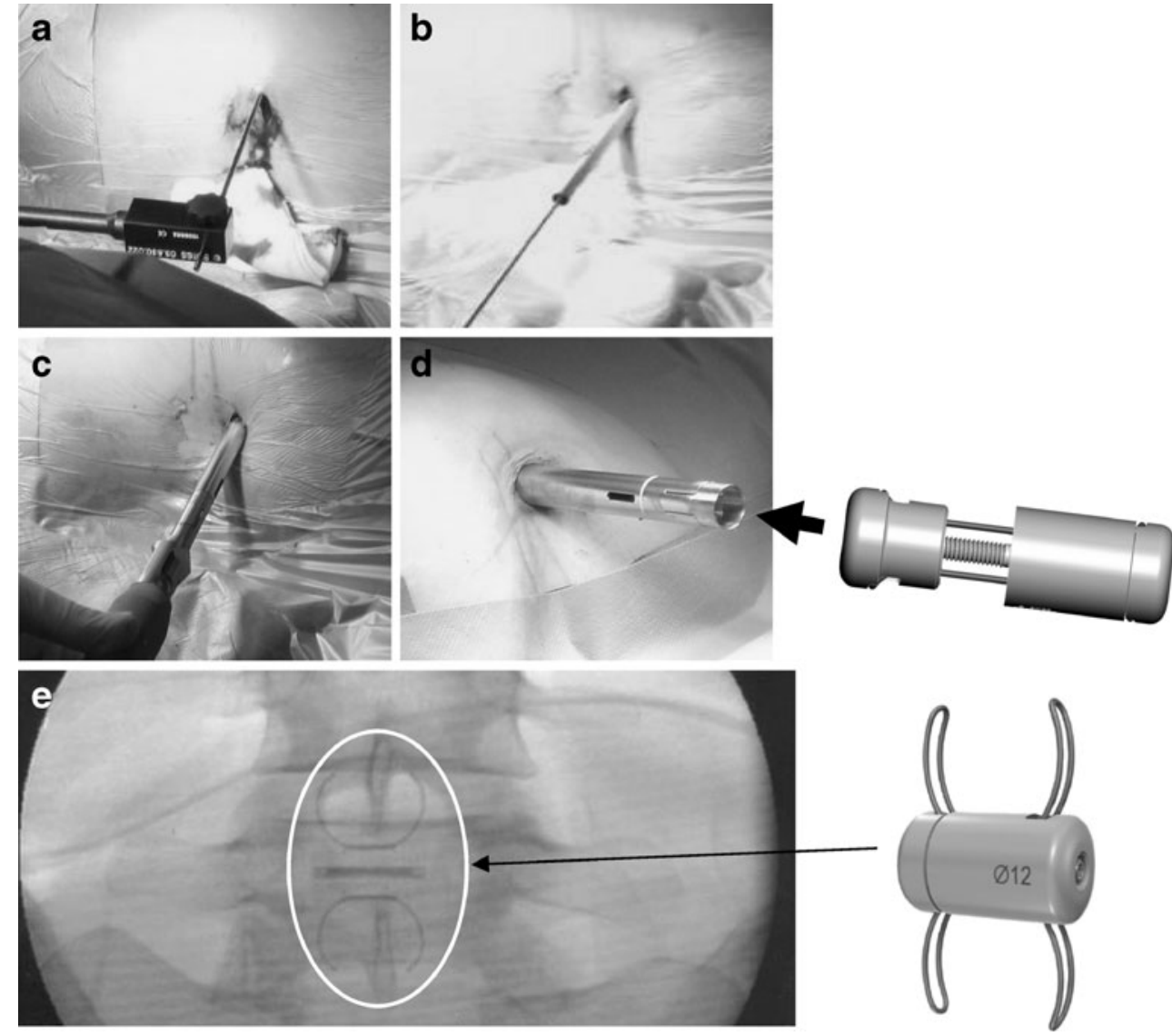
the case of postoperative problems only. Further follow-up included neuroexamination and assessment of pain, maximal pain-free walking distance (in the abovementioned categories) 6-8 weeks after surgery. Further reevaluation schedules included fixed and intermittent neurodeficit, pain and pain-free walking distance (in the abovementioned categories), subjective quality of life/contendness with surgery, further surgery or interventions, further imaging studies, and time to progression/recurrence of symptoms.

\section{Results}

\section{Surgery and complications}

Intraoperatively, a total of 87 In-space devices were implanted in 50 patients in up to three adjacent segments. Level L4/5 was operated most frequently (36 cases) followed by L3/4 (29), L2/3 (18), and L5/S1 (6). In two cases (L3/4 and L5/S1), implantation of the In-space was impossible because of strong ossification of the interspinous ligament. In one of these patients (L5/S1) who consequently did not improve after attempted implantation of the device microsurgical decompression was indicated, but refused by the patient. The other case (L3/54) was scheduled for In-space implantation at L2/3 and L3/4. The symptomatic of this patient, however, improved much after implantation of the device in L2/3 only (last follow-up of this patient was 17 months after surgery).

The size of the implanted In-space devices was $8 \mathrm{~mm}$ in $24,10 \mathrm{~mm}$ in $31,12 \mathrm{~mm}$ in 17 , and $14 \mathrm{~mm}$ in 8 cases. Intraoperatively, the spacer size was selected to compensate lumbar lordosis without provoking local kyphosis. Postoperative X-ray demonstrated dislocation of the implant in one case (L3/4), while two other implants in the same patient (L4/5 and L5/S1) were in place (Fig. 2). No further dislocations were observed. Other intrasurgical complications like spinous process fractures were likewise not observed. The average operation time was $16.4 \pm 12.2 \mathrm{~min}$ per segment. No blood cell concentrates had to be administered intraoperatively or postoperatively, and no intraoperative or postoperative severe adverse events were registered.

\section{Postoperative results}

During the hospitalization (1-2 days usually after surgery), two patients $(4 \%)$ complained about increased pain at the operation site or new-onset low back pain while the spinal claudication seemed relieved. These two patients were categorized as "worse." Eight patients (16\%) had no improvement of their symptoms and were categorized "same." Four patients $(8 \%)$ reported of some improvement of their symptoms ("slightly better"), and 36 patients $(72 \%)$ reported of good (31 patients, or $62 \%$ ) or excellent (symptom-free, 5 patients, or $10 \%$ ) relief of their symptoms.

\section{Follow-up}

During follow-up, 5 patients did not respond (two of which had additional low back pain, none with spondylolisthesis), and data of 45 patients $(90 \%)$ could be gathered completely. Average follow-up for these 45 patients was 1 year $(11.8 \pm$ 6.0 months). Patients who underwent second surgery in the operated segment were rated as failure of therapy and no longer followed. This happened during follow-up with 10 $(22 \%)$ of the patients. In these cases, decompression surgery and/or stabilization was performed. For the 10
Fig. 2 X-ray (a coronary plain and $\mathbf{b}$ sagittal plain) of implanted In-space devices in the levels L3/4, L4/5, and $\mathrm{L} 5 / \mathrm{S} 1$. The device in level L3/4 is the only dislocated device observed in our cohort (white arrow)
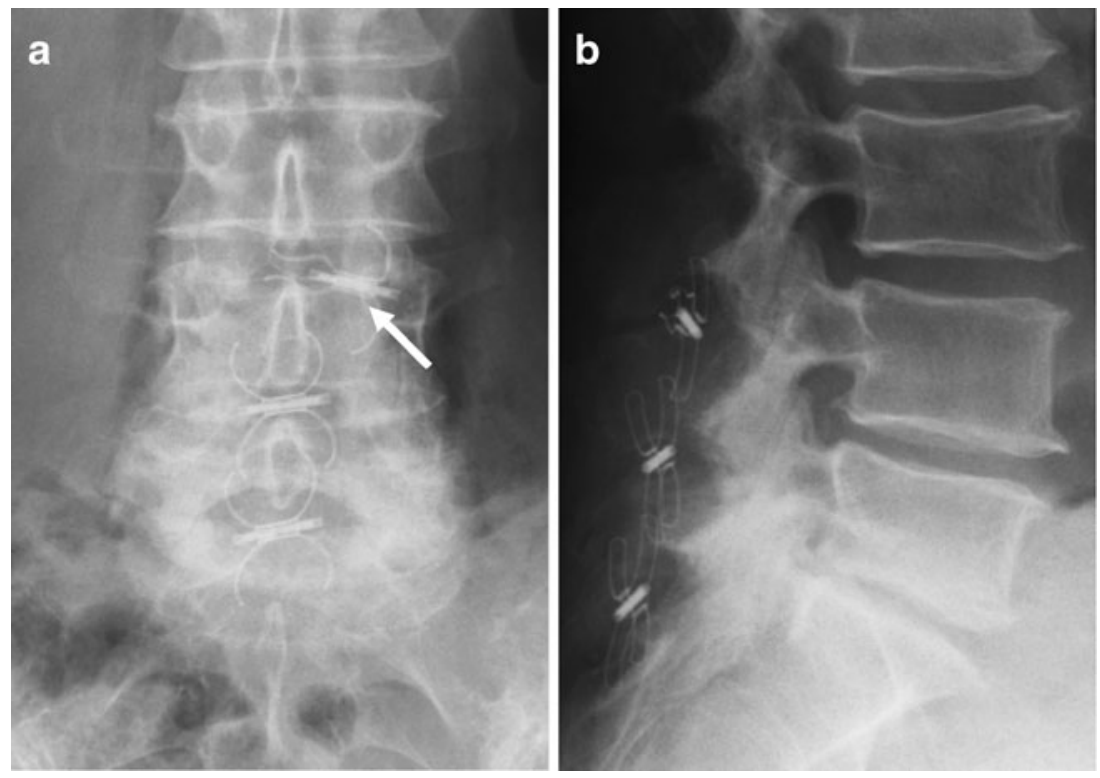
patients who underwent second surgery, average time between first and second surgery was $5 \pm 2$ months. Sixteen other patients $(35.5 \%)$ did report of recurrent spinal claudication, but were not yet scheduled for second surgery. Reasons for this were either that the patient did not (yet) wish a second procedure, or the presence of severe comorbidity and general unfitness for prolonged anaesthesia and more invasive procedures. At the time of writing up of this report, 19 patients (42.2\%) reported of lasting relief of their claudication and radicular pain without further treatment (Figs. 3 and 4). These patients had an average follow-up time of $12.2 \%$ (slightly longer than the average follow-up of the entire collective). However, 6 of these patients $(13.3 \%)$ complained about lasting $(2 / 45)$ or newonset (4/45) low back pain.

\section{Subgroup analysis}

Patients with spondylolisthesis in one to two segments showed fairly similar postoperative results compared with the average patient. Eight (66.7\%) of 12 patients in this subgroup reported of good or excellent relief of symptoms, $8.3 \%(1 / 12)$ experienced some relief ("slightly better"), and $25 \%$ experienced no positive effect at all ("same").

Twelve (70.6\%) of 17 patients presenting with additional low back pain experienced good or excellent initial reduction of symptoms, $5.9 \%$ (1/17) felt a slight relief,

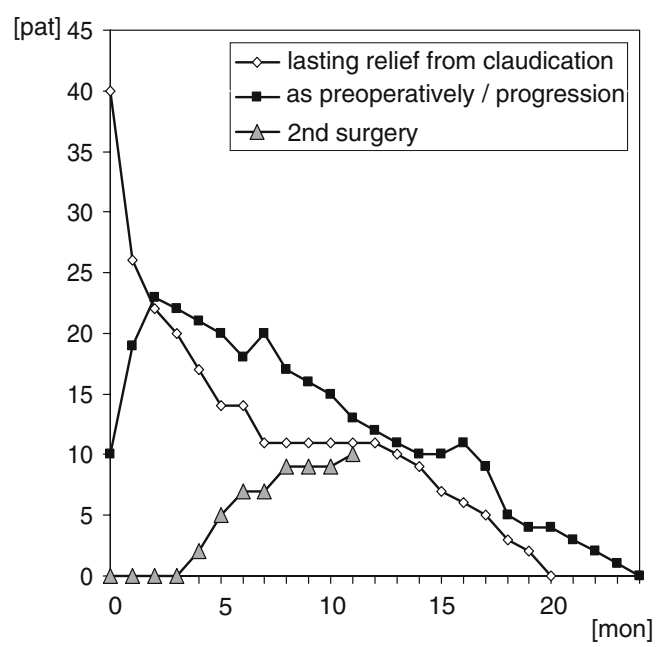

Fig. 3 Follow-up of patients who received an In-space device for lumbar spinal stenosis. At 3 months after surgery, the curve representing patients with recurrent symptoms rises above that of those with lasting relief from claudication. Afterward, both curves seem to parallel each other, suggesting a comparably stable ratio of patients with lasting relive/patients with progradient claudication always from 3 months onward. The sum of all curves decreases to the right of the diagram, because patients fall out of follow-up. A second surgery was first performed 4 months after In-space implantation. The second surgery curve breaks off after 11 months, when the last of so far 10 patients underwent second surgery

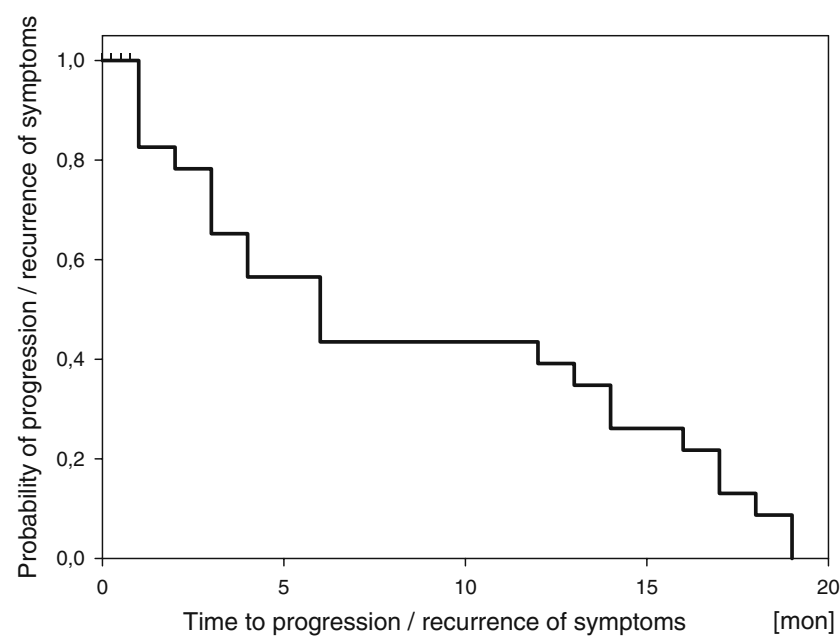

Fig. 4 Kaplan-Meier estimator for the time to progression/recurrence of symptoms after implantation of an In-space device in our cohort

$17.6 \%(3 / 17)$ noticed no significant change, and 5.9\% (1/17) reported of increased low back pain (Fig. 5a).

At last follow-up, the spondylolisthesis group was still doing fairly similar to the average patient, with $41.7 \%(5 / 12)$ reporting of lasting relief ( 1 of which complained about lasting low back pain), while $8.3 \%(1 / 12)$ underwent second surgery and $50 \%(6 / 12)$ complained of recurrent symptoms but were not (yet) scheduled for second surgery.

The patients with additional low back pain at first presentation fared likewise similar to the average patient. Forty percent (6/15) reported of lasting relief, $13.3 \%(2 / 15)$ of which did have lasting low back pain, whereas the other $26.7 \%(4 / 15)$ reported of lasting relief also for their low back pain. Forty percent $(6 / 15)$ had undergone second surgery, and 20\% (3/15) reported of recurrent symptoms but were not yet scheduled for second surgery (Fig. 5b).

\section{Discussion}

Techniques for surgical treatment of spinal stenosis

Conventional decompression surgery has demonstrated good results and can be regarded as gold standard in the treatment of lumbar spinal stenosis [1, 2, 7, 10, 18, 19, 29]. Short- and long-term results have been reported to be excellent, with more than $92.2 \%$ of patients still improved after 5.6 years [19]. However, the necessary removal of bone and soft tissue can have destabilizing effects on the operated segments, and the technique has therefore been combined with posterior lumbar fusion [11]. In order to provide additional stability, while avoiding longer operating times and potential risks of instrumentation with pedicle screws, rods, and intervertebral cages, interspinous 

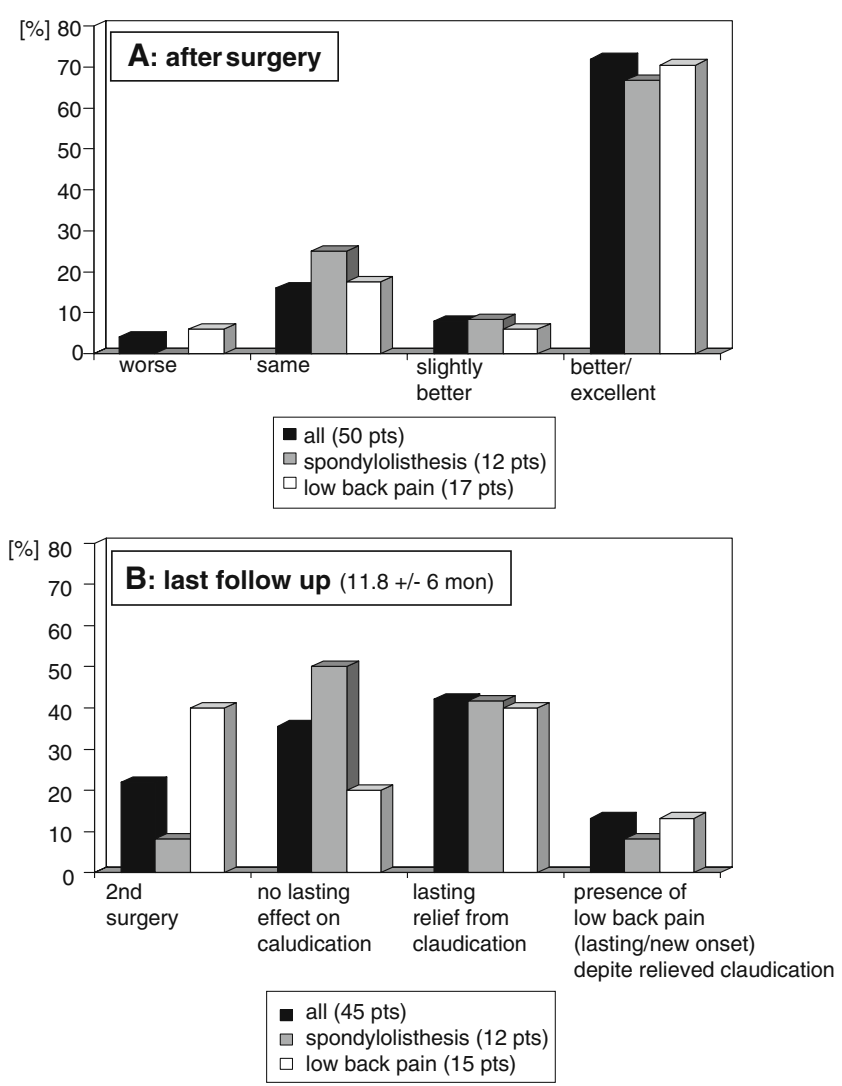

Fig. 5 a Results of a subgroup analysis directly after surgery. All groups [all patients, patients with spondylolisthesis only, and patients with (additional) low back pain at first presentation only] show a comparatively good response to surgery, with about $70 \%$ good or excellent results. b Situation at last follow-up (in average about 1 year later). Both subgroups do fairly similar concerning lasting relief from claudication. However, a significant number of these patients suffer from lasting or new-onset low back pain (last column in the diagram)

process implants have been developed. Wallis (Abbot spine, Austin, TX), Coflex (formerly Intraspinous U; Paradigm spine, New York, NY) [24], and Diam (Medtronic, Tolochenanz, Switzerland) were primarily designed to provide additional stability following conventional decompression surgery [13]. Combination of IDP with endoscopic decompression was described as a less invasive alternative [17].

In order to further minimize surgical trauma, IPD devices have been proposed as stand-alone technique, avoiding the need for conventional decompression surgery by indirect decompression through the distraction effect of the implant itself. The distraction of the posterior column of the spine (at level of the spinous processes and interspinous ligaments) leads to widening of foraminal diameter and reduces soft tissue compression of the spinal canal by stretching of the ligamentum flavum $[14,16]$. The X-stop (Medtronic, Tolochenanz, Switzerland) is so far the best studied device developed for this task [8, 23]. Recent developments like the Aperius PercLID (Kyphon, Sunny- vale, CA) and the In-space (applied in this study) are designed for percutaneous implantation, further reducing surgical trauma.

Intraoperative handling and complications

In our cohort the In-space device demonstrated short implanting times (average of only $16.4 \mathrm{~min}$ per segment in our cohort), virtually no blood loss and low complication rate (only $1.1 \%$ misplacements and $2.2 \%$ failed implantation because of severely calcified interspinous ligament).

Average implantation times for other IPD devices are not regularly reported in literature. Yano and colleagues [30] report of average operation times of $44.7 \mathrm{~min}$ per segment with a ceramic device, Kuchta and colleagues report that operation time for implantation of the X-stop was "much shorter when compared with the open decompression group" but give no exact values. The short implantation time of the In-space can be attributed to the percutaneous implantation.

The complication rates of other implants for IPD are likewise comparatively low. Barbagallo and colleagues [4] report $11.6 \%$ complications for the X-stop device (four device dislocations and four spinous process fractures in 69 patients), while Kuchta and colleagues [14] observed no intraoperative complications, using the same implant in 175 patients. Korovessis and colleagues [13] observed one involuntary dura leakage in 25 patients treated with the Wallis implant in combination with conventional decompression surgery.

\section{Outcome}

Unfortunately, we lack standardized outcome assessment (in the form of well-established questionnaires, etc.). However, like Verhoof and colleagues [27], we regarded pain reduction, neurological function an improvement of quality of life as the primary goals of IPD techniques, and defined reoperation as the end point of failure. The outcome in our cohort is comparable with those presented in the literature for other interspinous process implants such as the X-stop. Brussee and colleagues [5] report in their study of 65 patients who received an X-stop implant for lumbar spinal stenosis and spinal claudication without spondylolisthesis of $9.2 \%$ of reoperations within a follow-up period of $1.0 \pm 0.75$ years. Only $31.1 \%$ of the patients reported to be satisfied with their outcome. Likewise, Verhoof and colleagues [27] found good initial reduction of symptoms in 8 of 12 patients $(66.7 \%)$ treated for lumbar spinal stenosis in the presence of spondylolisthesis. Within 24 months (mean follow-up, 30.3 months), 3 (25\%) of these had recurrent symptoms and finally 7 patients $(58 \%)$ required reoperation (microsurgical decompression and 
posterolateral fusion). Our results should be expected to be somewhere in between these, because we included patients with and without presence of spondylolisthesis in the group. In our study, however, mild spondylolisthesis was not associated with a worse outcome compared with the entire collective.

Apart from this finding the similarity of the general outcome in our study compared with those cited above, using different implants suggests that the failure rate is an expression of the limits of the principle of IPD itself, rather than of individual design of the implants. The good initial response might be related to a surgical placebo effect, which was also recently observed in two prospective studies comparing vertebroplasty with sham operation $[6,12]$.

However, other authors report of far better results using the X-stop implant. Kuchta and colleagues [14] report of only 8 reoperations in 175 patients (4.6\%). The authors of this study suggest that this might partly be attributed to careful patient selection and application of functional (upright) magnetic resonance imaging for diagnosis. Likewise, other authors argue that implantation of IPD devices should primarily be considered in cases that present with typical spinal claudication with good reduction of pain under flexion of the lumbar spine only [15]. As most of these data are low-level evidence (like our own study), the last word concerning IPD cannot yet be spoken. However, presently there are 10 clinical trials with IPD devices going on [26], and it can be hoped that the remaining questions can be solved when these are completed.

Paralleling these findings, in our study of $42.2 \%$ patients with lasting relief from claudication and radicular symptoms, $13.3 \%$ suffered of lasting or new-onset lumbago. Whether the four cases of new-onset lumbago are a complication of In-space implantation or whether this belongs to the natural history of these patients cannot be identified by this retrospective analysis. These four patients, however, were the only ones who reported of this possible complication at last follow-up; none of the patients who did not experience lasting relief of claudication complained about new-onset or worsened low back pain at last followup. In the low back pain group in contrast, $26.7 \%$ of patients reported of lasting relief also for this symptom after In-space implantation. Thus, concerning the treatment of low back pain, no evident suggestion can be derived from this study.

The authors therefore suggest that in the presence of only this low-level evidence and the high recurrence rate, the device should primarily be used in clinical trials in order to get more information concerning the optimal indication. Patients who are anyway scheduled for implantation of an In-space should be carefully informed about the abovediscussed limitation before surgery.
However, a large controlled, prospective trial comparing the In-space device with the X-stop is under way and will supply a more detailed view of short- and long-term results of the In-space device [26].

\section{Conclusions}

The In-space device is a feasible and safe treatment option of spinal claudication in patients who do not tolerate microsurgical decompression surgery. The average operation time is very short, and intraoperative complications are rare. However, overall outcome showed lasting relief of claudication and radicular pain in only $42.2 \%$ after a median follow-up of about 1 year. This is far worse than has been shown even after long-term follow-up ( $>5$ years) of microsurgical decompression surgery $(>90 \%$ lasting relieve). Therefore, the authors suggest that at the time being, the device should primarily be used in clinical trials only, in order to get more information concerning the optimal indication.

No suggestions can be made concerning the treatment of low back pain, which might even progress after implantation of the device in some cases. The presence of mild spondylolisthesis (Meyerding ${ }^{\circ} 1$ ) did not show a negative effect on the outcome.

Acknowledgements Dr. Kantelhardt was supported by the EANS/ Synthes spine-fellowship 2008.

\section{References}

1. Amundsen T, Weber H, Nordal HJ, Magnaes B, Abdelnoor M, Lilleâs F (2000) Lumbar spinal stenosis: conservative or surgical management?: a prospective 10-year study. Spine 25(11):1424-35

2. Anjarwalla NK, Brown LC, McGregor AH (2007) The outcome of spinal decompression surgery 5 years on. Eur Spine J 16 (11):1842-7

3. Atlas SJ, Delitto A (2006) Spinal stenosis: surgical versus nonsurgical treatment. Clin Orthop Relat Res 443:198-207

4. Barbagallo GM, Olindo G, Corbino L, Albanese V (2009) Analysis of complications in patients treated with the X-Stop Interspinous Process Decompression System: proposal for a novel anatomic scoring system for patient selection and review of the literature. Neurosurgery 65(1):111-19

5. Brussee P, Hauth J, Donk RD, Verbeek AL (2008) Self-rated evaluation of outcome of the implantation of interspinous process distraction (X-Stop) for neurogenic claudication. Eur Spine J 17 (2):200-3

6. Buchbinder R, Osborne RH, Ebeling PR, Wark JD, Mitchell P, Wriedt C, Graves S, Staples MP, Murphy B (2009) A randomized trial of vertebroplasty for painful osteoporotic vertebral fractures. N Engl J Med 361(6):557-68

7. Castro-Menéndez M, Bravo Ricoy JA, Casal-Moro R, HernándezBlanco M, Jorge-Barreiro FJ (2009) Midterm outcome after microendoscopic decompressive laminotomy for lumbar spinal stenosis: 4-year prospective study. Neurosurgery 65(1):100-10 
8. Chiu JC (2006) Interspinous process decompression (IPD) system (X-STOP) for the treatment of lumbar spinal stenosis. Surg Technol Int 15:265-75

9. Chung SS, Lee CS, Kim SH, Chung MW, Ahn JM (2000) Effect of low back posture on the morphology of the spinal canal. Skeletal Radiol 29(4):217-23

10. Costa F, Sassi M, Cardia A, Ortolina A, De Santis A, Luccarell G, Fornari M (2007) Degenerative lumbar spinal stenosis: analysis of results in a series of 374 patients treated with unilateral laminotomy for bilateral microdecompression. J Neurosurg Spine 7(6):579-86

11. Gu Y, Chen L, Yang HL, Chen XQ, Dong RB, Han GS, Tang TS, Zhang ZM (2009) Efficacy of surgery and type of fusion in patients with degenerative lumbar spinal stenosis. J Clin Neurosci 16(10):1291-5

12. Kallmes DF, Comstock BA, Heagerty PJ, Turner JA, Wilson DJ, Diamond TH, Edwards R, Gray LA, Stout L, Owen S, Hollingworth W, Ghdoke B, Annesley-Williams DJ, Ralston SH, Jarvik JG (2009) A randomized trial of vertebroplasty for osteoporotic spinal fractures. N Engl J Med 361(6):569-79

13. Korovessis P, Repantis T, Zacharatos S, Zafiropoulos A (2009) Does Wallis implant reduce adjacent segment degeneration above lumbosacral instrumented fusion? Eur Spine J 18(6):830-40

14. Kuchta J, Sobottke R, Eysel P, Simons P (2009) Two-year results of interspinous spacer (X-Stop) implantation in 175 patients with neurologic intermittent claudication due to lumbar spinal stenosis. Eur Spine J 18(6):823-9

15. Lauryssen C (2007) Appropriate selection of patients with lumbar spinal stenosis for interspinous process decompression with the $\mathrm{X}$ STOP device. Neurosurg Focus 22(1):E5

16. Lindsey DP, Swanson KE, Fuchs P, Hsu KY, Zucherman JF, Yerby SA (2003) The effects of an interspinous implant on the kinematics of the instrumented and adjacent levels in the lumbar spine. Spine 28(19):2192-7

17. Liu G, Zhao JN, Dezawa A (2008) Endoscopic decompression combined with interspinous process implant fusion for lumbar spinal stenosis. Chin J Traumatol 11(6):364-7

18. Malmivaara A, Slätis P, Heliövaara M, Sainio P, Kinnunen H, Kankare J, Dalin-Hirvonen N, Seitsalo S, Herno A, Kortekangas $\mathrm{P}$, Niinimäki $\mathrm{T}$, Rönty $\mathrm{H}$, Tallroth $\mathrm{K}$, Turunen $\mathrm{V}$, Knekt $\mathrm{P}$, Härkänen T, Hurri H, Finnish Lumbar Spinal Research Group (2007) Surgical or nonoperative treatment for lumbar spinal stenosis? A randomized controlled tria. Spine 32(1):1-8

19. Oertel MF, Ryang YM, Korinth MC, Gilsbach JM, Rohde V (2006) Long-term results of microsurgical treatment of lumbar spinal stenosis by unilateral laminotomy for bilateral decompression. Neurosurgery 59(6):1264-9

20. Porter RW (1996) Spinal stenosis and neurogenic claudication. Spine 21(17):2046-52

21. Preston SD, Southall AR, Nel M, Das SK (2008) Geriatric surgery is about disease, not age. J R Soc Med 101(8):409-15

22. Sengupta DK, Herkowitz HN (2003) Lumbar spinal stenosis. Treatment strategies and indications for surgery. Orthop Clin North Am 34(2):281-95
23. Sobottke R, Schlüter-Brust $K$, Kaulhausen T, Röllinghoff $M$, Joswig B, Stützer H, Eysel P, Simons P, Kuchta J (2009) Interspinous implants (X Stop, Wallis, Diam) for the treatment of LSS: is there a correlation between radiological parameters and clinical outcome? Eur Spine J 18(10):1494-503

24. Tsai KJ, Murakami H, Lowery GL, Hutton WC (2006) A biomechanical evaluation of an interspinous device (Coflex) used to stabilize the lumbar spine. J Surg Orthop Adv 15(3): $167-72$

25. Turrentine FE, Wang H, Simpson VB, Jones RS (2006) Surgical risk factors, morbidity, and mortality in elderly patients. J Am Coll Surg 203(6):865-77

26. U.S. institutes of health. A study of the in-space device for treatment of moderate spinal stenosis. June 11, 2008. Available at: http://clinicaltrials.gov/. Accessed June 1, 2010.

27. Verhoof OJ, Bron JL, Wapstra FH, van Royen BJ (2008) High failure rate of the interspinous distraction device (X-Stop) for the treatment of lumbar spinal stenosis caused by degenerative spondylolisthesis. Eur Spine J 17(2):188-92

28. Vogt MT, Cawthon PM, Kang JD, Donaldson WF, Cauley JA, Nevitt MC (2006) Prevalence of symptoms of cervical and lumbar stenosis among participants in the Osteoporotic Fractures in Men Study. Spine 31(13):1445-51

29. Weinstein JN, Tosteson TD, Lurie JD, Tosteson AN, Blood E, Hanscom B, Herkowitz H, Cammisa F, Albert T, Boden SD, Hilibrand A, Goldberg H, Berven S, An H, SPORT Investigators (2008) Surgical versus nonsurgical therapy for lumbar spinal stenosis. N Engl J Med 358(8):794-810

30. Yano S, Hida K, Seki T, Aoyama T, Akino M, Iwasaki Y (2008) A new ceramic interspinous process spacer for lumbar spinal canal stenosis. Neurosurgery 63(1 Suppl 1):ONS108-13.

\section{Comment}

This study about interspinous devices is clear in its message: only a minority of cases of older patients with degenerative stenosis, not well operable by open surgery, profit from this little invasive implant at an average f-up of 1 year. 2-year-results would probably be even lower. Over enthusiastic publications in the past about similar interspinius devices, mainly led by consultants of the companies, are not credible in this reviewer's opinion, while this study is carefully performed and self-critically analysed. It shows the limits of "indirect" canal or foraminal decompression by interspinous distraction: there are anatomical limits (how much can be opened initially) and biomechanical limits (how long can the opening be maintained) as there is some erosion of the implantspinous process-interface.

Michael Payer

Geneva, Switzerland 